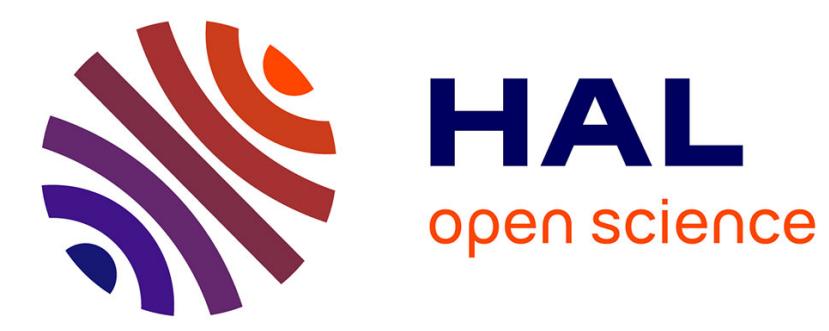

\title{
Particle-Phase Photosensitized Radical Production and Aerosol Aging
}

\author{
P. Arroyo, T. Bartels-Rausch, P. Alpert, S. Dumas, S. Perrier, C. George, M.
} Ammann

\section{> To cite this version:}

P. Arroyo, T. Bartels-Rausch, P. Alpert, S. Dumas, S. Perrier, et al.. Particle-Phase Photosensitized Radical Production and Aerosol Aging. Environmental Science and Technology, 2018, 52 (14), pp.7680-7688. 10.1021/acs.est.8b00329 . hal-01864961

\section{HAL Id: hal-01864961 https://hal.science/hal-01864961}

Submitted on 18 Nov 2020

HAL is a multi-disciplinary open access archive for the deposit and dissemination of scientific research documents, whether they are published or not. The documents may come from teaching and research institutions in France or abroad, or from public or private research centers.
L'archive ouverte pluridisciplinaire HAL, est destinée au dépôt et à la diffusion de documents scientifiques de niveau recherche, publiés ou non, émanant des établissements d'enseignement et de recherche français ou étrangers, des laboratoires publics ou privés. 


\title{
EDVIRONMTEDTAL
}

\section{Particle-Phase Photosensitized Radical Production and Aerosol Aging}

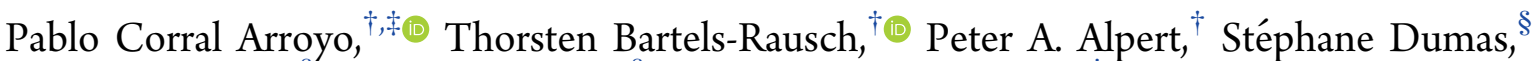 \\ Sébastien Perrier, ${ }^{\S}$ Christian George, ${ }^{\S(0)}$ and Markus Ammann*, ${ }^{*}(\mathbb{C}$ \\ ${ }^{\dagger}$ Paul Scherrer Institute, Laboratory of Environmental Chemistry, 5232 Villigen PSI, Switzerland \\ ${ }^{*}$ Department of Chemistry and Biochemistry, University of Bern, 2012 Bern, Switzerland \\ ${ }^{\S}$ CNRS, UMR5256, IRCELYON, Univ. Lyon, Université Claude Bernard Lyon 1, CNRS, IRCELYON, F-69626, Villeurbanne, \\ France
}

\section{Supporting Information}

\begin{abstract}
Atmospheric aerosol particles may contain light absorbing (brown carbon, $\mathrm{BrC}$ ), triplet forming organic compounds that can sustain catalytic radical reactions and thus contribute to oxidative aerosol aging. We quantify UVA induced radical production initiated by imidazole-2-carboxaldehyde (IC), benzophenone (BPh). and 4-benzoylbenzoic acid (BBA) in the presence of the nonabsorbing organics citric acid (CA), shikimic acid (SA), and syringol (Syr) at varying mixing ratios. We observed a maximum $\mathrm{HO}_{2}$ release of $10^{13}$ molecules $\min ^{-1} \mathrm{~cm}^{-2}$ at a mole ratio $X_{\mathrm{BPh}}<0.02$ for $\mathrm{BPh}$ in CA. Mixtures of either IC or BBA with CA resulted in $10^{11}-$ $10^{12}$ molecules $\mathrm{min}^{-1} \mathrm{~cm}^{-2}$ of $\mathrm{HO}_{2}$ at mole ratios $\left(X_{\mathrm{IC}}\right.$ and $X_{\mathrm{BBA}}$ ) between 0.01 and $0.15 . \mathrm{HO}_{2}$ release was affected by

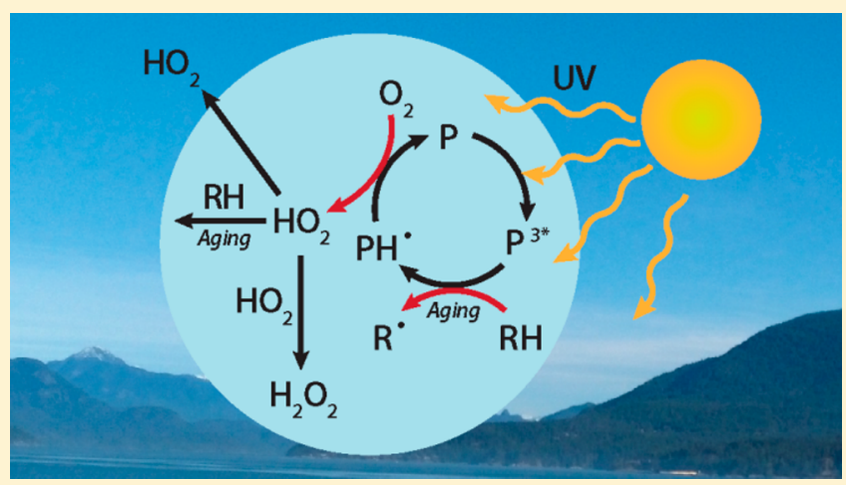
relative humidity $(R H)$ and film thickness suggesting coupled photochemical reaction and diffusion processes. Quantum yields of $\mathrm{HO}_{2}$ formed per absorbed photon for IC, BBA and $\mathrm{BPh}$ were between $10^{-7}$ and $5 \times 10^{-5}$. The nonphotoactive organics, Syr and $\mathrm{SA}$, increased $\mathrm{HO}_{2}$ production due to the reaction with the triplet excited species ensuing ketyl radical production. Rate coefficients of the triplet of IC with Syr and SA measured by laser flash photolysis experiments were $k_{\mathrm{Syr}}=(9.4 \pm 0.3) \times 10^{8}$ $\mathrm{M}^{-1} \mathrm{~s}^{-1}$ and $k_{\mathrm{SA}}=(2.7 \pm 0.5) \times 10^{7} \mathrm{M}^{-1} \mathrm{~s}^{-1}$. A simple kinetic model was used to assess total $\mathrm{HO}_{2}$ and organic radical production in the condensed phase and to upscale to ambient aerosol, indicating that $\mathrm{BrC}$ induced radical production may amount to an upper limit of 20 and $200 \mathrm{M} \mathrm{day}^{-1}$ of $\mathrm{HO}_{2}$ and organic radical respectively, which is greater or in the same order of magnitude as the internal radical production from other processes, previously estimated to be around $15 \mathrm{M}$ per day.
\end{abstract}

\section{INTRODUCTION}

Brown carbon $(\mathrm{BrC})$, defined as the fraction of organic compounds in atmospheric aerosol particles that absorb efficiently in the UVA-VIS range, is ubiquitously present in the troposphere. ${ }^{1-3}$ Absorption of solar radiation by $\mathrm{BrC}$ has been estimated at $0.1-0.25 \mathrm{~W} \mathrm{~m}^{-2}$ globally, which is approximately $25 \%$ of the radiative forcing by black carbon or soot. ${ }^{3}$ Photochemistry initiated by $\mathrm{BrC}$ species can change their own chemical composition and both enhance and decrease light absorption over time. ${ }^{4,5}$ These processes may be related to triplet forming $\mathrm{BrC}$ species, so-called photosensitizers, which may catalyze radical chain reactions. Photosensitized chemistry is well-established in aquatic photochemistry $^{6}$ and has been recently recognized as contributors to the oxidant budget in airborne particles. ${ }^{7-9}$ This may therefore represent an important contribution to aerosol aging, which refers to the chemical transformations induced by uptake of gas phase radicals such as $\mathrm{OH}, \mathrm{HO}_{2}$ or $\mathrm{NO}_{3}{ }^{7,10,11}$ to cloud droplets or particles, ${ }^{12}$ by partitioning of low volatility compounds following the oxidation of the precursors in the gas phase, and by condensed phase chemical processes. Recently, $\mathrm{HO}_{2}$ release in organic mixtures with imidazole-2-carboxaldehyde (IC) as photosensitizer and citric acid (CA) was determined as a function of relative humidity $(R H)$ and IC concentration. ${ }^{8}$ Here, we expand to another photosensitizer family and measure photosensitized $\mathrm{HO}_{2}$ release for IC, benzophenone (BPh) and 4-Benzoylbenzoic acid (BBA). In addition, we quantify the influence of different nonabsorbing compounds, shikimic acid (SA) and syringol (Syr) on the IC initiated $\mathrm{HO}_{2}$ release. Finally, we elucidate chemical cycling using a simple steady-state kinetic model to infer the internal $\mathrm{HO}_{2}$ and organic radical production. We evaluate the relative importance of internal photochemical

Received: January 18, 2018

Revised: May 29, 2018

Accepted: June 13, 2018

Published: June 13, 2018 
radical production in comparison to oxidant uptake from the gas phase and other internal sources.

Many known photosensitizers are carbonyls, which absorb above $300 \mathrm{~nm}$ especially when the carbonyl function is attached to an aromatic system. Figure 1 illustrates the catalytic

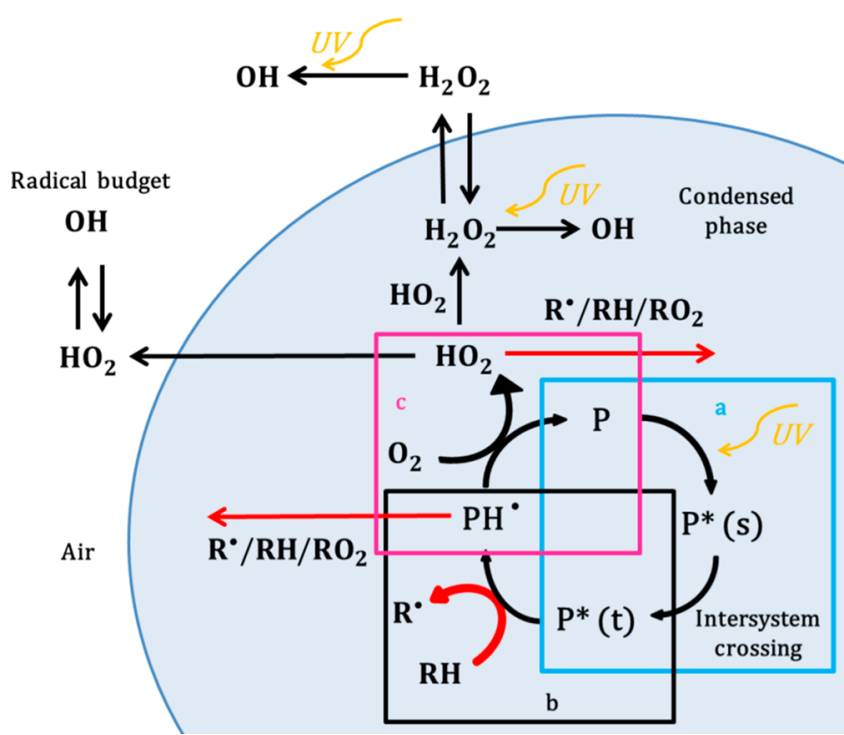

Figure 1. Photochemical catalytic cycle of a photosensitizer $(\mathrm{P})$ in a particle. (a) P first absorbs light being excited to the triplet state $\left(\mathrm{P}^{*}(\mathrm{t})\right)$. (b) The triplet reacts with an $\mathrm{H}$ atom/electron donor to produce the reduced ketyl radical $\left(\mathrm{PH}^{\bullet}\right)$. (c) The ketyl radical may transfer an $\mathrm{H}$ atom or electron to an acceptor, such as $\mathrm{O}_{2} . \mathrm{HO}_{2}$ radicals can then be released into the gas phase or react within the particle. Red reaction arrows indicate aging reactions of condensed phase organic molecules. Acid dissociation of $\mathrm{HO}_{2}$ is not shown for simplicity.

cycle of a photosensitizer (P) with an initial excitation step indicated by the blue box (box a), followed by singlet $\left(\mathrm{P}^{*}(\mathrm{~s})\right.$ ) to triplet $\left(\mathrm{P}^{*}(\mathrm{t})\right)$ intersystem crossing (ISC). $\mathrm{P}^{*}(\mathrm{t})$ state is long-lived and can act as an oxidant ${ }^{6}$ toward any organic compound (the "donor", RH), in the present study represented by CA, SA, and Syr. This leads to an alkyl or phenoxy radical and a ketyl radical $\left(\mathrm{PH}^{\bullet}\right)$ as illustrated in the black box $\mathrm{b}$ in Figure $1 . \mathrm{PH}^{\bullet}$ passes on an electron or hydrogen atom to oxygen or another electron acceptor (e.g., $\left.\mathrm{NO}_{2}\right)^{13}$ illustrated in the magenta box $\mathrm{c}$ in Figure 1 and leads back to $\mathrm{P}$ in its ground state. The efficiency of the catalytic cycle is reduced by several processes involving $\mathrm{P}^{*}(\mathrm{~s})$ and $\mathrm{P}^{*}(\mathrm{t})$ such as deactivation of $\mathrm{P} *(\mathrm{~s})$, deactivation of $\mathrm{P} *(\mathrm{t})$, that is, by phosphorescence, nonradiative decay, and reaction with oxygen. Radical reactions of $\mathrm{PH}^{\bullet}$ also influence the efficiency of the catalytic cycle. Overall, formation of $\mathrm{P} *(\mathrm{t})$ leads to the oxidation of $\mathrm{RH}$ and to the production of $\mathrm{HO}_{2}$. Therefore, this indirect photochemistry may drive oxidation under those daytime tropospheric conditions that are characterized by low flux at wavelengths below $300 \mathrm{~nm}$, where direct photolysis of the majority of organic compounds is not possible and $\mathrm{HO}_{x}$ production in the gas phase is not efficient.

Imidazoles, which include $\mathrm{IC}$, are $\mathrm{BrC}$ compounds formed as products from the multiphase chemistry of glyoxal and ammonium sulfate (AS) in aqueous aerosols. ${ }^{9,14,15}$ Glyoxal is an important oxygenated volatile organic compound (OVOC) originating from the oxidation of predominantly biogenic precursors. $\mathrm{BPh}, \mathrm{BBA},{ }^{6}$ and other aromatic carbonyls may be formed as intermediates in the photooxidation of aromatic compounds in the gas phase ${ }^{16,17}$ or also by condensed phase oxidation of biomass burning products. ${ }^{18,19} \mathrm{CA}$ serves as a proxy for nonabsorbing, highly oxidized and functionalized secondary organic compounds in the atmosphere. In solution, CA takes up or releases water gradually without phase change over the whole range of relative humidity $(R H)$ values studied here, ${ }^{20,21}$ which makes it a good substrate and matrix from an experimental perspective. SA is considered a proxy for reactive oxygenated organic material and has been found in biomass burning aerosol. ${ }^{22}$ It is condensed phase ozonolysis kinetics has been investigated previously. ${ }^{23-25}$ Syr is a well-known thermal decomposition product of lignin occurring in biomass burning aerosol from hard woods ${ }^{26,27}$ and known to act as a singleelectron reductant with $\mathrm{NO}_{2}$ and other oxidants. ${ }^{28,29}$

\section{EXPERIMENTAL SECTION}

Coated-Wall Flow Tube Experiments. The $\mathrm{HO}_{2}$ release was measured by scavenging $\mathrm{HO}_{2}$ with an excess of nitrogen monoxide (NO) in an irradiated reactor containing a laminar coated wall flow tube (CWFT). The method has been described in detail in our previous work ${ }^{8}$ and further details, raw data from exemplary experiments and the rationale of the conversion of the measured $\mathrm{NO}$ loss to $\mathrm{HO}_{2}$ release rate are given in the SI. The coated tubes were $1.2 \mathrm{~cm}$ inner diameter, $50 \mathrm{~cm}$ long (Duran glass) and fitted snuggly into the reactor as inserts. The jacketed glass reactor held at $T=20 \pm 1{ }^{\circ} \mathrm{C}$ was surrounded by 7 fluorescent lamps (UVA range, Philips Cleo Effect $20 \mathrm{~W}=300-420 \mathrm{~nm}, 41 \mathrm{~cm}, 2.6 \mathrm{~cm}$ o.d., see Figure S1), leading to $\mathrm{J}_{\mathrm{NO}_{2}}$ of $0.011 \mathrm{~s}^{-1}$ in the flow tube. Flows of $\mathrm{N}_{2}$ and $\mathrm{O}_{2}$ were set by mass flow controllers at $1 \mathrm{~L} / \mathrm{min}$ and $0.5 \mathrm{~L} /$ $\mathrm{min}$, respectively. $\mathrm{NO}$ was added with a third flow of 5-10 $\mathrm{mL} / \mathrm{min}$ of $100 \mathrm{ppm}$ of $\mathrm{NO}$ in $\mathrm{N}_{2}$. The $\mathrm{NO}$ concentration during CWFT experiments was always in excess of $10^{13}$ molecules $\mathrm{cm}^{-3}$ to efficiently scavenge $99 \%$ of $\mathrm{HO}_{2}$ produced by the films within at most $50 \mathrm{~ms}\left(k_{1}=8.0 \times 10^{-12} \mathrm{~cm}^{3}\right.$ molecule ${ }^{-1} \mathrm{~s}^{-1}$ at $\left.298 \mathrm{~K}^{30} t_{99 \%}=\frac{-\ln (0.01)}{k_{1}[\mathrm{NO}]}\right)$. The lifetime of $\mathrm{HO}_{2}$ with respect to its self-reaction in the gas phase is about $20 \mathrm{~s}\left(\left[\mathrm{HO}_{2}\right]=5 \mathrm{ppb}\right.$ and $k_{\mathrm{HO}_{2}}=1.8 \times 10^{-12} \mathrm{~cm}^{3}$ molecule $^{-1}$ $\mathrm{s}^{-1}$ at $298 \mathrm{~K}^{31}$

$$
\mathrm{NO}+\mathrm{HO}_{2} \rightarrow \mathrm{NO}_{2}+\mathrm{OH}
$$

$\mathrm{RH}$ from 25 to $65 \%$ at $20{ }^{\circ} \mathrm{C}$ was controlled using two different humidifier apparatus, in which the carrier gas passed either through a permeable tube immersed in liquid water at $T$ $>293 \mathrm{~K}$ or over liquid water at $T<293 \mathrm{~K}$ to a desired dew point. The flow was directed to bypass the reactor to exchange flow tubes without the need to interrupt the flow system and to determine the initial trace gas levels at the entrance of the CWFT. The concentration of $\mathrm{NO}$ was measured by a chemiluminescence detector (Ecophysics CLD 77 AM). $\mathrm{H}_{2} \mathrm{O}_{2}$ was measured by the AeroLaser 2021 analyzer.

The preparation of the films composed of IC and CA and their properties are described in our previous work. ${ }^{8}$ The IC/ $\mathrm{CA}, \mathrm{BPh} / \mathrm{CA}$, and BBA/CA films were produced by depositing $400 \mu \mathrm{L}$ of aqueous solutions of $0.75 \mathrm{M}$ of $\mathrm{CA}$ and varying amounts of $\mathrm{IC}, \mathrm{BPh}$, or $\mathrm{BBA}$ in the glass tube inserted. A homogeneous, thin and viscous film in equilibrium with the same $\mathrm{RH}$ as used later in the experiment was achieved by rolling and turning the tube in all directions at room temperature under a gentle flow of humidified $\mathrm{N}_{2}$. Solutions 
were prepared prior to each experiment and kept in the dark. The thickness of the film after equilibration with the given $\mathrm{RH}$ was estimated from the hygroscopic volume growth factors of $\mathrm{CA}^{21}$ assuming that the water content was dominated by the properties of CA. Final concentrations in the film were $5 \mathrm{M}$ of CA, $0.1-0.6 \mathrm{M}$ for IC and BBA and $0.02-0.1 \mathrm{M}$ for BPh at $35 \%$ RH. For CWFT experiments with SA and Syr the mole ratio $\mathrm{IC} /(\mathrm{CA}+\mathrm{SA})$ and $\mathrm{IC} /(\mathrm{CA}+\mathrm{Syr})$ was kept constant at 0.15 at $40 \% \mathrm{RH}$, while increasing SA and Syr concentrations. Conditions of CWFT experiments are summarized in Table S1. Blank experiments run with noncoated tubes were routinely performed in between experiments with coated tubes and always resulted in NO losses below detection limit. In order to exclude other sources of $\mathrm{HO}_{2}$, films composed only of IC were irradiated, which did not result in detectable NO loss. A commercial $\mathrm{O}_{3}$ analyzer (Photometric $\mathrm{O}_{3}$ Analyzer Model 400E; TELEDYNE Instruments) was used to check the absence of $\mathrm{O}_{3}$ (detection limit $2 \mathrm{ppb}$ ).

Aerosol Flow Tube Experiments. An irradiated aerosol flow tube (AFT) experiment was also used in the exact same configuration as the CWFT experiments to measure $\mathrm{HO}_{2}$ release from IC/CA particles. The AFT is $156 \mathrm{~cm}$ long, 7 $\mathrm{cm}$ inner diameter and fabricated with Teflon perfluoroalkoxy copolymer (PFA). Lamps for irradiation (UVA range, Philips Cleo Effect $70 \mathrm{~W}=300-420 \mathrm{~nm}, 150.7 \mathrm{~cm}, 2.8 \mathrm{~cm}$ o.d., emission spectrum identical to those of CWFT, Figure S1) resulted in a $J_{\mathrm{NO}_{2}}$ value of $0.011 \mathrm{~s}^{-1}$. Gas flow in the AFT consisted of $0.8 \mathrm{~L} / \mathrm{min}$ of $\mathrm{N}_{2}, 0.2 \mathrm{~L} / \mathrm{min}$ of $\mathrm{O}_{2}$, and a third flow of $\mathrm{NO} / \mathrm{N}_{2}$ to maintain the $\mathrm{NO}$ concentration at $\sim 2.5 \times 10^{13}$ molecules $\mathrm{cm}^{-3}$. A particle filter downstream of the AFT was used to prevent particles from entering the NO analyzer. More details on the experimental procedure and exemplary raw data are shown in the SI.

Laser Flash Photolysis Experiments. The decay rate of the excited triplet state of IC in the presence of SA and Syr was measured in aqueous solution by laser flash photolysis (LFP), as described in detail in the SI.

Chemicals. The chemicals used were imidazole-2-carboxaldehyde (>99\%, Aldrich), benzophenone (>99\%, Aldrich), 4benzoylbenzoic acid (>99\%, Aldrich), citric acid (Fluka), shikimic acid (Alfa Aesar, 98\%), and 2,6-dimethoxyphenol (99\%, Aldrich). The water used was Milli-Q water $(18 \mathrm{~m} \Omega)$.

\section{RESULTS}

Influence of Photosensitizer Type and Mixing Ratio. Figure 2 presents the $\mathrm{HO}_{2}$ radical release in the CWFT as a function of the photosensitizer/CA mole ratio at constant CA mass $(76.8 \mathrm{mg})$ at a $\mathrm{RH}$ of $43-47 \%$ for IC and $53-57 \%$ for $\mathrm{BPh}$ and $\mathrm{BBA}$. The largest $\mathrm{HO}_{2}$ release of $10^{13}$ molecules $\mathrm{cm}^{-2}$ $\mathrm{min}^{-1}$ was due to the $\mathrm{BPh} / \mathrm{CA}$ mixture at a $X_{\mathrm{BPh}}$ of 0.025 and decreased to $1.6 \times 10^{12}$ molecules $\mathrm{cm}^{-2} \mathrm{~min}^{-1}$ at a $X_{\mathrm{BPh}}$ of 0.002 . The $\mathrm{HO}_{2}$ release for the mixture of BBA/CA was $(0.2-$ $0.7) \times 10^{12}$ molecules $\mathrm{cm}^{-2} \mathrm{~min}^{-1}$, while for the mixture of IC/ CA the release amounted to $(0.1-0.3) \times 10^{12}$ molecules $\mathrm{cm}^{-2}$ $\mathrm{min}^{-1}$ for mole ratios $\left(X_{\mathrm{BBA}}\right.$ and $\left.X_{\mathrm{IC}}\right)$ between 0.02 and 0.08 and $0.03-0.13$, respectively. Despite $\mathrm{BPh}$ having the lowest absolute concentration, it resulted in the greatest $\mathrm{HO}_{2}$ release reflecting its larger absorbance at wavelengths $>320 \mathrm{~nm}$ (Figure S1) and more efficient radical production.

The measurements of the $\mathrm{HO}_{2}$ release as a function of film thickness (Figure S7) ${ }^{8}$ exhibits an increase until around $3 \mu \mathrm{m}$ and then tends to level off or decrease until $5.5 \mu \mathrm{m}$. This

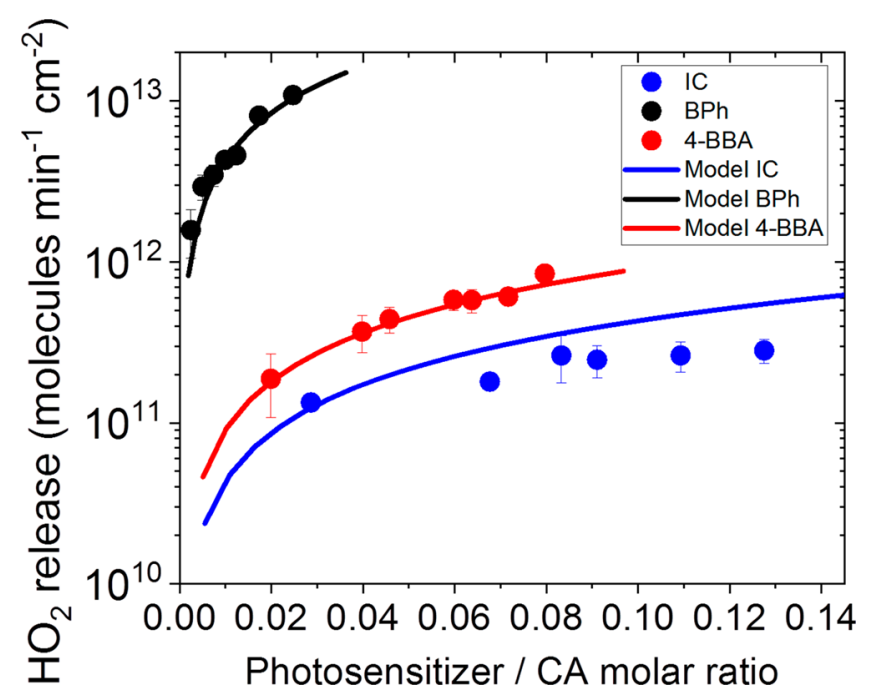

Figure 2. Measured $\mathrm{HO}_{2}$ radical release as a function of the ratio of photosensitizer to citric acid (CA) for BPh at $45 \% \mathrm{RH}, 4-\mathrm{BBA}$ at $45 \%$ $\mathrm{RH}$, and IC at 55\% RH (black, red, and blue symbols, respectively). Error bars are determined from the standard deviation of several replicate measurements. Solid lines are fits using the model described in the text.

indicates that (i) the primary excitation is occurring predominantly throughout the bulk of the film and that (ii) the observed $\mathrm{HO}_{2}$ release is contributed from the upper $3 \mu \mathrm{m}$. The fact that the roughly linear initial increase of $\mathrm{HO}_{2}$ with film thickness exhibits a small offset may indicate a surface contribution, as discussed below. These results are consistent with the AFT measurements shown in Figure S8, where we observed 2 orders of magnitude more $\mathrm{HO}_{2}$ release per unit mass likely due to the shorter depth, from which $\mathrm{HO}_{2}$ molecules leave the condensed phase.

The absence of $\mathrm{O}_{3}$ and the fact that the amount of $\mathrm{HONO}$ formed was nearly half of the NO loss (see SI) is a strong indication that $\mathrm{HO}_{2}$ was actually the dominant oxidant. Photolysis of HONO was too slow $\left(J_{\mathrm{HONO}}=0.0024 \mathrm{~s}^{-1}\right)$ to initiate additional gas phase radical chemistry. Measurements were done over $100 \mathrm{~h}$ of irradiation for IC/CA without any significant drop of the $\mathrm{HO}_{2}$ release, which confirms the photocatalytic nature of the process. We cannot entirely exclude secondary chemistry of the oxidized donor that may lead to elimination of $\mathrm{HO}_{2}$ and thus contribute to NO loss.

Influence of Relative Humidity. Figure 3 shows the $\mathrm{HO}_{2}$ release at constant dry masses of $\mathrm{CA}$ and constant mole ratio of photosensitizers as a function of RH (Figure 3a). As RH increases from about $40 \%, \mathrm{HO}_{2}$ release decreases by about 1 order of magnitude for IC, BBA and $\mathrm{BPh}$. However, the trends of $\mathrm{HO}_{2}$ release are dissimilar among the three below $40 \% \mathrm{RH}$. For IC/CA and RH increasing from 0 to $20 \%$ the $\mathrm{HO}_{2}$ release increases to a plateau of $2 \times 10^{11}$ molecules $\mathrm{cm}^{-2} \mathrm{~min}^{-1}$ at $\mathrm{RH}$ between 20 and $40 \%$. In contrast, for $\mathrm{BBA} / \mathrm{CA}$ and $\mathrm{BPh} / \mathrm{CA}$, $\mathrm{HO}_{2}$ fluxes are much higher for dry conditions and then decrease toward $40 \% \mathrm{RH}$.

Quantum yields of observed $\mathrm{HO}_{2}$ release per absorbed photon for these experiments calculated based on absorption and lamp emission spectra (Figure S1) are shown in Figure 3b. In the high $\mathrm{RH}$ region, the quantum yield is highest for IC and lowest for BBA, possibly caused by a lower ISC yield, faster deactivation of $\mathrm{P}^{*}(\mathrm{t})$, additional sinks for $\mathrm{PH}^{\bullet},{ }^{33}$ lower rate of 

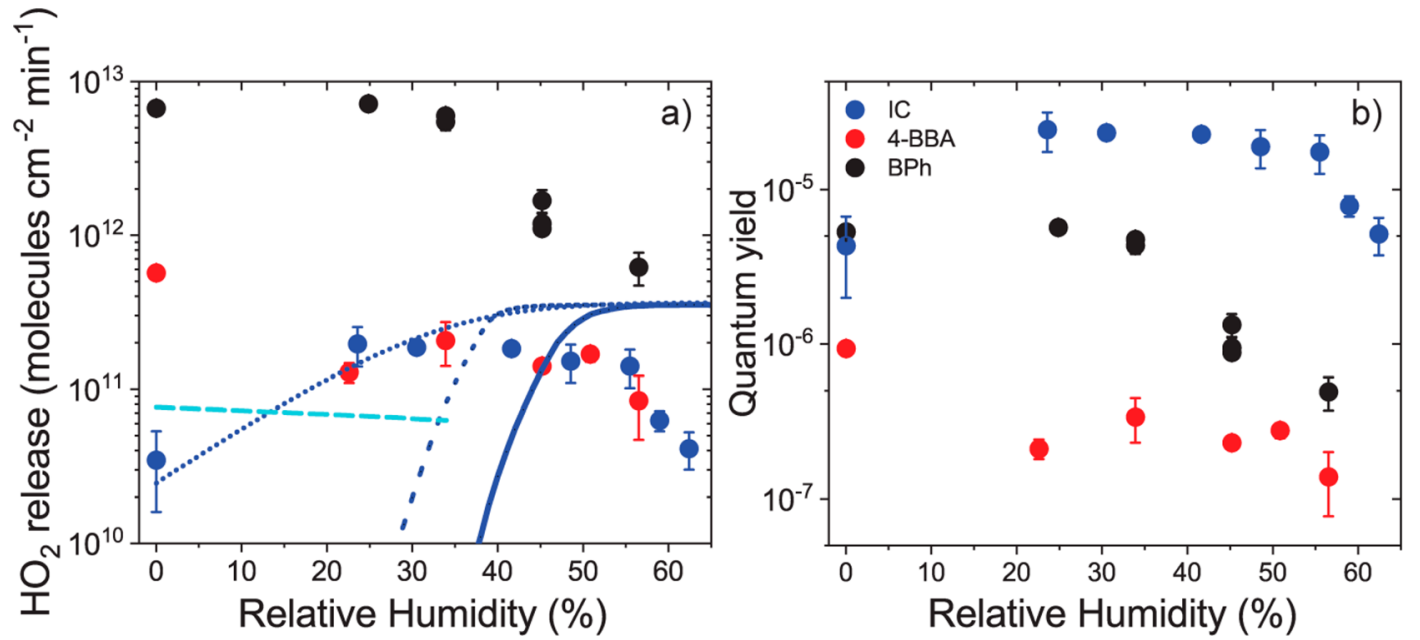

Figure 3. (a) Measured $\mathrm{HO}_{2}$ release (symbols) as a function of $\mathrm{RH}$ at a fixed mole ratio of photosensitizer to $\mathrm{CA}$ (0.08 for BPh, 0.08 for 4-BBA, 0.11 for IC). Blue lines show model calculations for the case of IC based on the parametrization of the diffusion coefficient by Lienhard et al., ${ }^{32}$ with and without an assumed water activity dependence of the rate coefficient for the $\mathrm{HO}_{2}$ self-reaction (dashed and solid line, respectively). The blue dotted line represents the model prediction with adjusted diffusivity. The dashed purple line represents a suspected surface reaction. See text for more details. (b) Quantum yield $\mathrm{HO}_{2}$ release of versus $\mathrm{RH}$ for the same experiments. Error bars are determined from the standard deviation of several replicate measurements.

the reaction between $\mathrm{P} *(\mathrm{t})$ and $\mathrm{CA}$ or competing processes, such as secondary chemistry of $\mathrm{HO}_{2}$.

The observed RH dependence (Figure 3a) may be qualitatively understood in the context of $\mathrm{RH}$ driven water activity to dilute or concentrate the reactants, to affect the viscosity and thus molecular diffusion, and likely by phase separation occurring at low $\mathrm{RH}$. At RH between $40 \%$ and $60 \%$, where the mixtures with CA are presumably homogeneous solutions, water activity increases, which we expected to control the decrease of the $\mathrm{HO}_{2}$ production for all three photosensitizers due to the decreasing concentrations of donor, triplets, and radical intermediates caused by the dilution by water. At low RH (low water activity) little change in volume and thus donor concentration occurs, but the viscosity of the films increases, ${ }^{34}$ which we expected to lead to decreasing $\mathrm{HO}_{2}$ production and release because of low diffusivity of all involved species. The complex interplay of these effects will be examined together with the kinetic model in the Discussion section.

When different types of organic matter (BBA and $\mathrm{BPh}$ mixed with $C A$ ) are present in aqueous solution, they may phase separate, which we hypothesize to occur for BBA and $\mathrm{BPh}$ between 0\%-20\% RH and 35-40\% RH, respectively, due to differences in polarity and solubility, similar to cases of organic solutes mixed with inorganic salts. ${ }^{35-37}$ Phase separation may lead to an accumulation of the more surface active photosensitizers at the film-air interface increasing its local concentration there and thus increasing reaction rates of $\mathrm{P}^{*}(\mathrm{t})$ or $\mathrm{PH}^{\bullet}$ and thereby also the $\mathrm{HO}_{2}$ release into the gas phase. Due to this complication, we only consider the IC-CA system in our further more quantitative discussion of the behavior under dry conditions.

Influence of Competing Donors. Figure 4 shows the $\mathrm{HO}_{2}$ release for the two systems IC/Syr/CA and IC/SA/CA as a function of the Syr or SA donor concentration. Experiments employed constant IC and CA concentration at 0.7 and $6 \mathrm{M}$, respectively. For comparison, observed $\mathrm{HO}_{2}$ release for the IC/CA system without any additional donor is shown as the blue line in Figure 4. At a concentration around $10^{-4} \mathrm{M}$ for Syr

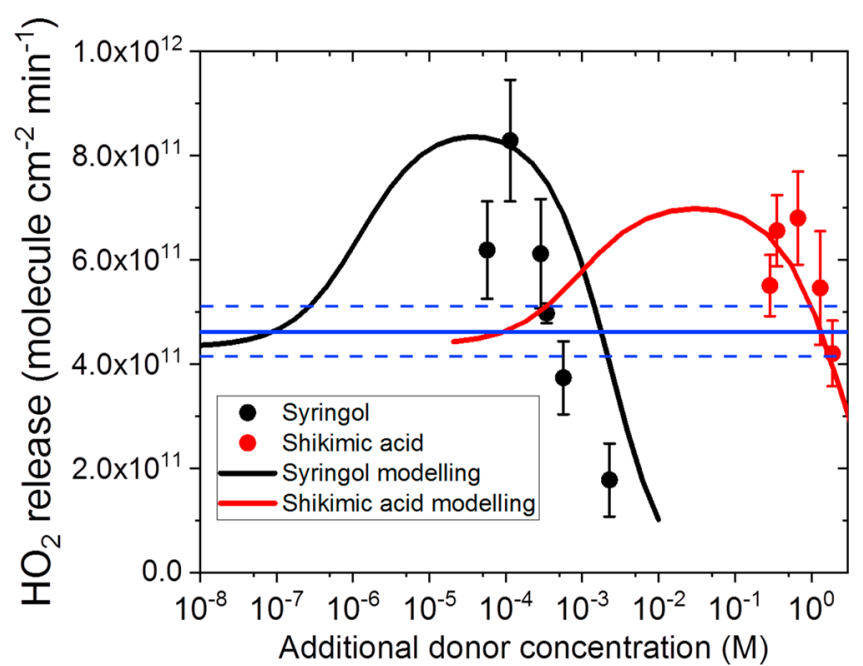

Figure 4. $\mathrm{HO}_{2}$ radical release photosensitized by IC in the presence of citric acid and Syr (black squares) and SA (red circles) as additional competing donors, respectively, both at constant IC $(0.7 \mathrm{M})$ and CA (6 M) load at $45 \% \mathrm{RH}$. Error bars are determined from the standard deviation of several replicate measurements. Black and red lines represent the $\mathrm{HO}_{2}$ release returned by the kinetic model described in the text for Syr and SA, respectively. The blue line and dashed lines indicate the measured $\mathrm{HO}_{2}$ release and the error range, respectively, in absence of any additional donor apart from CA.

and $0.5 \mathrm{M}$ for $\mathrm{SA}, \mathrm{HO}_{2}$ release was enhanced compared to experiments using $\mathrm{IC} / \mathrm{CA}$. In turn, $\mathrm{HO}_{2}$ release decreases by about a factor of 5 as the donor concentration increases further by a factor of about 50 .

The enhancement of the $\mathrm{HO}_{2}$ release at low additional donor concentration may result from increased $\mathrm{PH}^{\bullet}$ production, that is, the additional donors compete with $\mathrm{CA}$ for oxidation by $\mathrm{P}^{*}(\mathrm{t})$. The concentration at which Syr and SA provide faster $\mathrm{PH}^{\bullet}$ production is related to the ratio between the rate coefficient of the $\mathrm{P}^{*}(\mathrm{t})$ with $\mathrm{CA}$ and that of the IC triplet with either of the additional donors. These rate coefficients were measured by laser flash photolysis (LFP) as 
shown in Figure S6: $k_{\mathrm{SA}}=(2.7 \pm 0.5) \times 10^{7} \mathrm{M}^{-1} \mathrm{~s}^{-1}$ for SA $(\mathrm{pH}=7)$ and $k_{\text {Syr }}=(9.4 \pm 0.3) \times 10^{8} \mathrm{M}^{-1} \mathrm{~s}^{-1}$ for Syr $(\mathrm{pH}=$ 6.5). The rate coefficient of the reaction between the $\mathrm{P}^{*}(\mathrm{t})$ and

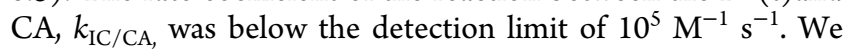
note that $k_{\mathrm{Syr}}$ is about 36 times greater than $k_{\mathrm{SA}}$. Though, the concentration ranges of Syr and $\mathrm{SA}$, at which enhanced $\mathrm{HO}_{2}$ and its drop was observed, differ by a factor of 1000, implying that additional chemical reactions, such as those of $\mathrm{PH}^{\bullet}$ and $\mathrm{HO}_{2}$ with the donors or their oxidation products, for example, peroxy radicals, may also be important, as discussed further below with the kinetic model.

\section{DISCUSSION}

As mentioned above, we expected that the $\mathrm{RH}$ dependence would be mainly driven by the water activity changing with $\mathrm{RH}$ leading at first to the following two effects: (i) The increasing water activity and thus increasing volume of the film leads to decreasing volumetric concentrations of $\mathrm{CA}, \mathrm{P}^{*}(\mathrm{t})$, and $\mathrm{PH}^{\bullet}$ and thus of resulting reaction rates. (ii) Water acts as a plasticizer for viscous aqueous organic solutions, leading to decreasing viscosity with increasing water content and thus molecular diffusion coefficients increasing by many orders of magnitude from low to high $\mathrm{RH}^{34}$ We evaluate the complex interplay of reaction and diffusion with a kinetic model for the overall mechanism shown in Figure 5 to adjust some of the

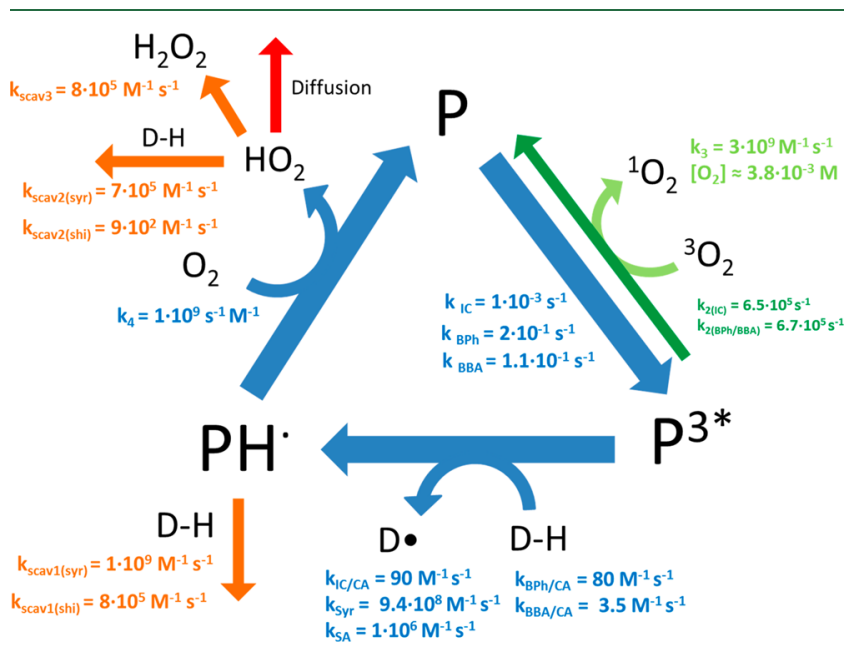

Figure 5. Catalytic mechanism and rate coefficients for the photochemistry of photosensitizers IC, BBA, BPh with a CA and the other $\mathrm{H}$ atom donors SA and Syr. Labels for photosensitizer and donors are the same as in Figure 1. Reaction rate coefficients are defined in the SI.

parameters that are not known for the present high solute strength system, to estimate the internal radical turnover and to allow upscaling to atmospheric conditions.

The water activity dependent diffusion coefficient of $\mathrm{HO}_{2}$ $\left(D_{\mathrm{HO}_{2}}\right)$ was first estimated by extrapolating from the data of $\mathrm{H}_{2} \mathrm{O}$ diffusion in CA solutions by Lienhard et al. ${ }^{32,38}$ (Figure S10, SI). The other parameter values included in Figure 5 were obtained or estimated as described in the SI (Table S2). We first tried to adjust the model to the data of Figure 2 at $55 \%$ $\mathrm{RH}$ and those for the thickness dependence in Figure S7 with the rate coefficients $k_{\mathrm{IC} / \mathrm{CA}}, k_{\mathrm{BPh} / \mathrm{CA}}, k_{\mathrm{BBA} / \mathrm{CA}}$, respectively, as the only free variables, because they control $\mathrm{PH}^{\bullet}$ production and strongly influence the calculated $\mathrm{HO}_{2}$ release, as at $55 \% \mathrm{RH}$ the system was not expected to be under diffusion control. The values estimated in this way for $k_{\mathrm{IC} / \mathrm{CA}}, k_{\mathrm{BPh} / \mathrm{CA}}$ and $k_{\mathrm{BBA} / \mathrm{CA}}$ were 90,80 , and $3.5 \mathrm{M}^{-1} \mathrm{~s}^{-1}$, respectively. Understandably, they are much lower than for electron rich aromatics in the range $10^{5}-10^{9} \mathrm{M}^{-1} \mathrm{~s}^{-1}$. ${ }^{6,39}$ There is not enough literature data to compare the relative reactivities among the three sensitizers. The low value for $k_{\mathrm{IC} / \mathrm{CA}}$ is also consistent with the upper limit obtained from the LFP experiments, $<10^{5} \mathrm{M}^{-1} \mathrm{~s}^{-1} . k_{\mathrm{IC} / \mathrm{CA}}$ was then used to calculate the $\mathrm{HO}_{2}$ release for the $\mathrm{RH}$ dependence data (solid line in Figure 3a). Obviously, the calculated $\mathrm{HO}_{2}$ release exhibits the expected maximum at intermediate $\mathrm{RH}$ in Figure $3 \mathrm{a}$, but completely fails in predicting the observed slopes at low and high $\mathrm{RH}$. The sharp falloff of the calculated $\mathrm{HO}_{2}$ release is due to $D_{\mathrm{HO}_{2}}$ dropping by 6 orders of magnitude between $60 \%$ and $20 \% \mathrm{RH}$. Related to that, the model also fails to predict the thickness dependence measured at $36 \% \mathrm{RH}$. On the other hand the model strongly overpredicts $\mathrm{HO}_{2}$ release at high $\mathrm{RH}$. We note that solubility of $\mathrm{O}_{2}$ in organic solvents, such as ethanol, propanol or carboxylic acids, is higher than in water. ${ }^{40}$ Thus, $\mathrm{O}_{2}$ solubility decreases in the transition from a CA rich solution at low $\mathrm{RH}$ to a more $\mathrm{H}_{2} \mathrm{O}$ rich solution at higher RH (Figure S9). However, the change in $\mathrm{O}_{2}$ concentration is only about $20 \%$, and due to the significant rate of triplet scavenging by $\mathrm{O}_{2}$, the lower $\mathrm{O}_{2}$ concentration increases the triplet concentration with higher water activity and thus compensates the dilution effect. Below 50\% $\mathrm{RH}$ the decrease in the diffusion controls the decrease of $\mathrm{HO}_{2}$, and not oxygen solubility, since $D$ drops several orders of magnitude down to $0 \% \mathrm{RH}$.

The inability of the model to explain the $\mathrm{RH}$ dependent reactivity may be related to a dependence of the many rate coefficients on the activity of the reactants (solute strength effects) and also on viscosity. The first suspect was the selfreaction of $\mathrm{HO}_{2}, k_{\text {scav3 }}$, motivated by the significant dependence of its gas phase rate coefficient with water vapor pressure. $^{41}$ Keeping with the diffusivity as before we parametrized $k_{\text {scav3 }}$ as a function of $\mathrm{RH}$ (see SI) leading to a much lower $\mathrm{HO}_{2}$ self-reaction rate at lower $\mathrm{RH}$. As a result, the model fits improve with respect to the $\mathrm{RH}$ dependence down to around $40 \% \mathrm{RH}$ (dashed line in Figure 3a) and with respect to the thickness dependence (measured at 36\% RH, dashed line in Figure $\mathrm{S} 7$ ). Below 50\% $\mathrm{RH}$, diffusion is limiting the $\mathrm{HO}_{2}$ release, which leads to increasing $\mathrm{HO}_{2}$ concentration and thus increasing sensitivity to the value of $k_{\text {scav3 }}$. At high $R H$, the self-reaction rate is not relevant enough due to fast diffusion of $\mathrm{HO}_{2}$ out of the film and thus low steady state $\mathrm{HO}_{2}$ concentrations, so that the change in $k_{\text {scav3 }}$ does not improve the fit in that range. Also, below $40 \% \mathrm{RH}$, the drop of $\mathrm{D}_{\mathrm{HO}_{2}}$ dominates the falloff of the modeled $\mathrm{HO}_{2}$ release.

Motivated by the occurrence of rate limiting surface reactions at low $\mathrm{RH}$ in many other multiphase reaction systems, ${ }^{25,38,42}$ we added a surface $\mathrm{HO}_{2}$ production term proportional to the IC concentration adjusted to the thickness dependence in Figure S7 (dashed cyan line). This would provide an explanation for the small offset of the observed linear dependence of the $\mathrm{HO}_{2}$ release with thickness below 2 $\mu \mathrm{m}$. The same surface reactivity would then dominate the low $\mathrm{RH}$ range in Figure 3a (dashed cyan line). The slight decrease with increasing $\mathrm{RH}$ comes from the decrease in IC concentration with increasing water content. Apparently, such a surface process could explain the order of magnitude of $\mathrm{HO}_{2}$ release at low $\mathrm{RH}$, but in absence of further constraints we refrain from suggesting an explicit RH dependent surface 
reaction model. We also note that such a surface process could also result from phase separation with higher reactivity than expected for a homogeneously mixed system. As an alternative to suggest a surface process and water activity dependence of $k_{\text {scav3, }}$, we also evaluated the effect of an alternative parametrization of $D_{\mathrm{HO}_{2}}$. (Figure S9, dotted line in Figure 3a, dotted line in Figure S7). The results indicate that $D_{\mathrm{HO}_{2}}$ would need to be 4 orders of magnitude higher than that based on the Lienhard et al. data under dry conditions to explain the measured $\mathrm{HO}_{2}$. In turn, this scenario would be less consistent with the measured thickness dependence of the $\mathrm{HO}_{2}$ release. In summary, based on the available data and this sensitivity analysis, we are not able to conclusively decide whether the higher than expected $\mathrm{HO}_{2}$ releases at low $\mathrm{RH}$ are due to changes in $D_{\mathrm{HO}_{2}}, k_{\text {scav3 }}$, the occurrence of a surface process or a combination thereof.

While we do not assume the medium to affect the initial excitation, ISC may be affected by reduced rotational freedom at high viscosity, ${ }^{43}$ leading to increasing ISC yield from low to high $\mathrm{RH}$. There is evidence that hydrogen bonded transition states are involved in electron transfer, ${ }^{44}$ proton coupled electron transfer ${ }^{45}$ and hydrogen abstraction reactions. ${ }^{45}$ This could lead to rates strongly increasing with water activity, not only for $k_{\text {scav3 }}{ }^{41}$ but also for the self-reaction of $\mathrm{PH}^{\bullet},{ }^{45}$ their reaction with other organics ${ }^{46}$ and the quenching reactions between triplets and organics. ${ }^{47}$ As discussed above, while the water activity dependence of $k_{\text {scav3 }}$ may help to explain the $\mathrm{HO}_{2}$ release at $30-40 \% \mathrm{RH}$, the $\mathrm{HO}_{2}$ self-reaction is not relevant at high $\mathrm{RH}$. Therefore, the strong drop in $\mathrm{HO}_{2}$ release between $45 \%$ and $65 \% \mathrm{RH}$ must be the consequence of the water activity dependence of ISC, radical source and radical sink processes, in which the sinks (scavenging reactions of $\mathrm{PH}^{\bullet}$ and $\mathrm{HO}_{2}$ ) are increasing more strongly with water activity than the sources. In absence of reliable information about solute strength effects on these processes, we refrain from using additional ill-constrained parameters in an attempt to fit to the data. We, therefore, use the parameters valid in the $40-50 \%$ $\mathrm{RH}$ range for the remainder of the discussion.

For the experiments with Syr and SA shown in Figure 4, all parameters were kept fixed, except $k_{\mathrm{SA}}$ and $k_{\mathrm{Syr}}$, to reasonably well reproduce the transition from $\mathrm{HO}_{2}$ release enhancement by Syr and SA into that of $\mathrm{HO}_{2}$ scavenging toward higher concentrations. The value of $k_{\mathrm{SA}}$ had been adjusted downward from $(2.7 \pm 0.5) \times 10^{7} \mathrm{M}^{-1} \mathrm{~s}^{-1}$ as determined in the LFP experiments to $1 \times 10^{6} \mathrm{M}^{-1} \mathrm{~s}^{-1}$. This may be justified by the differences in viscosity for the CWFT (10 Pa s at $40 \% \mathrm{RH}^{34}$ ) and the LFP experiments (0.001 Pa s), since electron-transfer reactions may slow down from low to high viscosity. ${ }^{44}$ Second, $\mathrm{pH}$ in the CWFT and LFP was 1.2 and 7, respectively. Deprotonated acids may undergo 1 order of magnitude faster electron transfer reactions ${ }^{48}$ so that $k_{\mathrm{SA}}$ measured at $\mathrm{pH}=7$ likely overestimates the reactivity for the CWFT experiments. In contrast to SA, Syr neither protonates nor deprotonates at $\mathrm{pH}$ conditions between the two experiments and thus, values of $k_{\mathrm{Syr}}$ are not expected to be affected by the different $\mathrm{pH}$ values. Since no reduction in $k_{\mathrm{Syr}}$ compared to its values measured by LFP was required to achieve comparable agreement with observations in Figure 4, $\mathrm{pH}$ seems to be the dominant factor affecting the reactivity of the IC triplet with Syr and SA under our conditions.

The fate of $\mathrm{PH}^{\bullet}$ is the reaction with organics (Syr or SA), ${ }^{49}$ self-recombination ${ }^{46}$ and reaction with $\mathrm{O}_{2}$ to produce $\mathrm{HO}_{2}$.
This means that $\mathrm{PH}^{\bullet}$ production is fundamental to explain $\mathrm{HO}_{2}$ production in the condensed phase. This internal radical turnover in the presence of an efficient triplet-state scavenger is substantiated in Figure 6 showing the modeled total

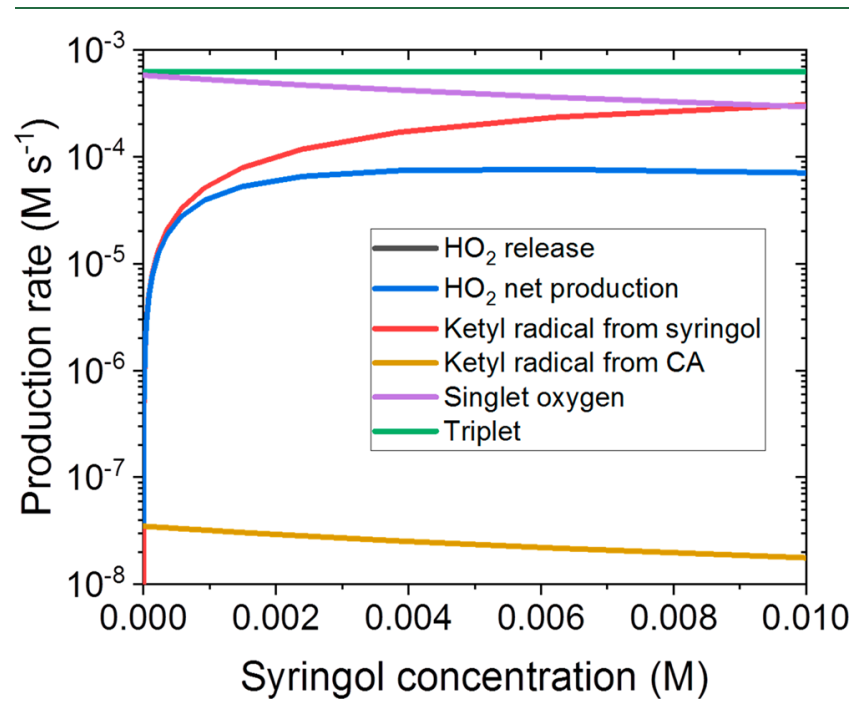

Figure 6. Estimated production of IC ketyl radical, singlet oxygen, IC triplet and $\mathrm{HO}_{2}$, in the condensed phase film as well as $\mathrm{HO}_{2}$ release into the gas phase for IC and CA with increasing concentrations of Syr at the same conditions as the CWFT experiments performed with Syr (Figure 4).

production rate of $\mathrm{HO}_{2}$ in the condensed phase and flux to the gas phase for the conditions of the experiments with Syr presented above at $40 \% \mathrm{RH}$. Production of $\mathrm{PH}^{\bullet}$ from the reaction with $\mathrm{CA}$ and Syr, singlet oxygen and triplet state of IC are also included in Figure 6. The $\mathrm{H}_{2} \mathrm{O}_{2}$ release to the gas phase predicted by the model is about $10^{9}$ molecules $\mathrm{cm}^{-2}$ $\min ^{-1}\left(10^{-9} \mathrm{M} \mathrm{s}^{-1}\right)$, unfortunately below the detection limit of the $\mathrm{H}_{2} \mathrm{O}_{2}$ detector used in our experiments.

The internal $\mathrm{HO}_{2}$ production is predicted to be 3 orders of magnitude greater than its release (dark blue and black lines, respectively, in Figure 6), mostly due to slowed diffusion and the competing scavenging reactions discussed above. The organic radical production is another factor of 10 higher than that of $\mathrm{HO}_{2}$. Note that as the Syr concentration increases, $\mathrm{PH} \bullet$ production increases (red line) while singlet oxygen production decreases (violet line) (Figure 6) implying that radicals, both organic radicals and $\mathrm{HO}_{2}$, may be preserved and lead to an increasing oxidative capacity within the particle at high organic donor concentration. In the sense of an overall uncertainty estimate, we note that when the ISC is reduced to its lower limit of 0.1 , the estimated $k_{\mathrm{IC} / \mathrm{CA}}$ would have to be increased by a factor of 10 to match with the observations, which would lead to a corresponding reduction of radical production. Even so, with either more reactive donors, or higher concentrations of those similar to Syr, the overall radical production may get comparable.

Upscaling to Atmospheric Conditions. Photochemistry of triplet forming $\mathrm{BrC}$ is an important source of radicals in the condensed phase as clearly demonstrated in this study for IC, $\mathrm{BBA}$, and $\mathrm{BPh}$ in combination with different oxidation targets. The mass absorption coefficient (MAC) reported by Zhong and $\operatorname{Jan}^{50}$ for a biomass burning aerosol indicates that roughly $9000 \mathrm{~mol}$ of photons per liter of liquid phase of aerosol are absorbed per day assuming $500 \mathrm{~nm}$ diameter particles with 
chromophore concentrations of $1 \mathrm{M}$. This yields an upper limit for triplet production of $900 \mathrm{M} \mathrm{day}^{-1}$ considering 0.1 as quantum yield for triplet production. ${ }^{33}$ The absorbance of the mixtures used in this study would lead to similar MAC values as those reported by Zhong and Jan. ${ }^{50}$ Mass based upper limits of $\mathrm{HO}_{2}$ release observed in this study were $4.2 \times 10^{16}, 1.4 \times$ $10^{17}$, and $1.4 \times 10^{18}$ molecule per hour and gram, for IC, BBA, and $\mathrm{BPh}$, respectively. We upscale these fluxes by assuming a suspended aerosol mass of $20 \mu \mathrm{g} \mathrm{m}^{-3}$, a $12 \mathrm{~h}$ irradiation cycle with sinusoidal intensity profile at $0^{\circ}$ zenith angle and the ratio of the excitation rates of the photosensitizers from the sun spectrum and that used in our experiments $\left(j_{\text {sun }} / j_{\text {lamps }}=2.83\right.$, 0.51 , and 0.53 for IC, BBA, and $\mathrm{BPh}$, respectively). This leads to an $\mathrm{HO}_{2}$ release of $2.4 \times 10^{12}, 1.4 \times 10^{12}$, and $1.5 \times 10^{13}$ molecules $\mathrm{m}^{-3} \mathrm{~h}^{-1}$ for IC, 4-BBA, and $\mathrm{BPh}$, respectively. These remain far below the full sunlight tropospheric gas phase $\mathrm{HO}_{2}$ productivity of $10^{17}$ molecules $\mathrm{m}^{-3} \mathrm{~h}^{-1}$. ${ }^{17}$ Though, they may become relevant in heavy pollution episodes ${ }^{8}$ or when not much light $<300 \mathrm{~nm}$ driving gas phase radical production is available.

As demonstrated in Figure 6, depending on the presence of more reactive organic oxidation targets (such as electron rich aromatics occurring in biomass burning particles) the total internal radical turnover may exceed the $\mathrm{HO}_{2}$ release by 4 orders of magnitude. The total condensed phase internal radical production was around up to $10^{17}$ molecules $\mathrm{m}^{-3} \mathrm{~h}^{-1}$. Considering the same assumed aerosol population and light yields an estimated condensed phase $\mathrm{HO}_{2}$ production of $10^{16}$ molecule $\mu \mathrm{g}^{-1} \mathrm{~h}^{-1}$, which is about $10^{25}$ molecule $\mathrm{L}^{-1} \mathrm{~h}^{-1}$ in the condensed phase or an upper limit of $200 \mathrm{M} \mathrm{day}^{-1}$. For a typical gas phase concentration of $10^{6} \mathrm{OH}$ radicals $\mathrm{cm}^{-3}$ during the day, its flux into the condensed phase is about $10^{10}$ molecules $\mathrm{cm}^{-2} \mathrm{~s}^{-1}$ or $10^{2}$ molecule $\mathrm{s}^{-1}$ into a particle 500 $\mathrm{nm}$ in diameter yielding a volume averaged maximum turnover of about $0.2 \mathrm{M} \mathrm{day}^{-1}$. Other radical sources, mainly Fenton chemistry and photolysis of $\mathrm{NO}_{3}{ }^{-}$and $\mathrm{H}_{2} \mathrm{O}_{2}$ contribute about $15 \mathrm{M}$ per day. ${ }^{52}$ Therefore, the indirect photochemical radical source addressed here may play an important role in aerosol aging. Clearly, the relative importance of triplet oxidation on aerosol aging may depend on the triplet forming efficiency of real chromophores, size and the microphysical properties of the aerosol particles, and could be clarified by measurements of triplet concentrations in ambient particles. ${ }^{53}$

\section{ASSOCIATED CONTENT}

\section{S Supporting Information}

The Supporting Information is available free of charge on the ACS Publications website at DOI: 10.1021/acs.est.8b00329.

Description of the lamps spectrum, solar actinic flux, and absorption spectrum of the compounds used; conversion from NO loss to $\mathrm{HO}_{2}$ release; details about laser flash photolysis experiments; results from thickness dependence experiments; results from AFT experiments; and details of the kinetic model construction (PDF)

\section{AUTHOR INFORMATION}

\section{Corresponding Author}

*Phone: +41 56310 4049. E-mail: markus.ammann@psi.ch. ORCID $\odot$

Pablo Corral Arroyo: 0000-0003-4090-1623

Thorsten Bartels-Rausch: 0000-0002-7548-2572

Christian George: 0000-0003-1578-7056
Markus Ammann: 0000-0001-5922-9000

\section{Notes}

The authors declare no competing financial interest.

\section{ACKNOWLEDGMENTS}

We would like to thank Laura Gonzalez and Rainer Volkamer for helpful discussions, Mario Birrer for technical support, M.A., P.A., and P.C.A. appreciate support by the Swiss National Science Foundation (Grant 163074). P.A. thanks for funding from the European Union's Horizon 2020 research and innovation program under the Marie Skłodowska-Curie grant agreement No 701647.

\section{REFERENCES}

(1) Kirchstetter, T. W.; Thatcher, T. L. Contribution of organic carbon to wood smoke particulate matter absorption of solar radiation. Atmos. Chem. Phys. 2012, 12 (14), 6067-6072.

(2) Hoffer, A.; Gelencsér, A.; Guyon, P.; Kiss, G.; Schmid, O.; Frank, G. P.; Artaxo, P.; Andreae, M. O. Optical properties of humic-like substances (HULIS) in biomass-burning aerosols. Atmos. Chem. Phys. 2006, 6 (11), 3563-3570.

(3) Laskin, A.; Laskin, J.; Nizkorodov, S. A. Chemistry of atmospheric brown carbon. Chem. Rev. 2015, 115 (10), 4335-82.

(4) Lee, H. J.; Aiona, P. K.; Laskin, A.; Laskin, J.; Nizkorodov, S. A. Effect of Solar Radiation on the Optical Properties and Molecular Composition of Laboratory Proxies of Atmospheric Brown Carbon. Environ. Sci. Technol. 2014, 48 (17), 10217-10226.

(5) Wong, J. P. S.; Nenes, A.; Weber, R. J. Changes in Light Absorptivity of Molecular Weight Separated Brown Carbon Due to Photolytic Aging. Environ. Sci. Technol. 2017, 51 (15), 8414-8421.

(6) Canonica, S.; Hellrung, B.; Wirz, J. Oxidation of phenols by triplet aromatic ketones in aqueous solution. J. Phys. Chem. A 2000, 104 (6), 1226-1232.

(7) George, C.; Ammann, M.; D’Anna, B.; Donaldson, D. J.; Nizkorodov, S. A. Heterogeneous Photochemistry in the Atmosphere. Chem. Rev. 2015, 115 (10), 4218-4258.

(8) González Palacios, L.; Corral Arroyo, P.; Aregahegn, K. Z.; Steimer, S. S.; Bartels-Rausch, T.; Nozière, B.; George, C.; Ammann, M.; Volkamer, R. Heterogeneous photochemistry of imidazole-2carboxaldehyde: $\mathrm{HO}_{2}$ radical formation and aerosol growth. Atmos. Chem. Phys. 2016, 16 (18), 11823-11836.

(9) Yu, L.; Smith, J.; Laskin, A.; Anastasio, C.; Laskin, J.; Zhang, Q. Chemical characterization of SOA formed from aqueous-phase reactions of phenols with the triplet excited state of carbonyl and hydroxyl radical. Atmos. Chem. Phys. 2014, 14 (24), 13801-13816.

(10) Shiraiwa, M.; Yee, L. D.; Schilling, K. A.; Loza, C. L.; Craven, J. S.; Zuend, A.; Ziemann, P. J.; Seinfeld, J. H. Size distribution dynamics reveal particle-phase chemistry in organic aerosol formation. Proc. Natl. Acad. Sci. U. S. A. 2013, 110 (29), 11746-11750.

(11) Herrmann, H.; Ervens, B.; Jacobi, H. W.; Wolke, R.; Nowacki, P.; Zellner, R. CAPRAM2.3: A chemical aqueous phase radical mechanism for tropospheric chemistry. J. Atmos. Chem. 2000, 36 (3), 231-284.

(12) Herrmann, H.; Schaefer, T.; Tilgner, A.; Styler, S. A.; Weller, C.; Teich, M.; Otto, T. Tropospheric Aqueous-Phase Chemistry: Kinetics, Mechanisms, and Its Coupling to a Changing Gas Phase. Chem. Rev. 2015, 115 (10), 4259-4334.

(13) Stemmler, K.; Ammann, M.; Donders, C.; Kleffmann, J.; George, C. Photosensitized reduction of nitrogen dioxide on humic acid as a source of nitrous acid. Nature 2006, 440 (7081), 195-198.

(14) Aregahegn, K. Z.; Nozière, B.; George, C. Organic aerosol formation photo-enhanced by the formation of secondary photosensitizers in aerosols. Faraday Discuss. 2013, 165, 123.

(15) Kampf, C. J.; Jakob, R.; Hoffmann, T. Identification and characterization of aging products in the glyoxal/ammonium sulfate system; implications for light-absorbing material in atmospheric aerosols. Atmos. Chem. Phys. 2012, 12 (14), 6323-6333. 
(16) Atkinson, R.; Arey, J. Atmospheric Chemistry of Gas-phase Polycyclic Aromatic Hydrocarbons: Formation of Atmospheric Mutagens. Environ. Health Perspect. 1994, 102, 117-126.

(17) Olariu, R. I.; Barnes, I.; Becker, K. H.; Klotz, B. Rate coefficients for the gas-phase reaction of $\mathrm{OH}$ radicals with selected dihydroxybenzenes and benzoquinones. Int. J. Chem. Kinet. 2000, 32 (11), 696-702.

(18) Decesari, S.; Facchini, M. C.; Matta, E.; Mircea, M.; Fuzzi, S.; Chughtai, A. R.; Smith, D. M. Water soluble organic compounds formed by oxidation of soot. Atmos. Environ. 2002, 36 (11), 18271832.

(19) Graham, B. Water-soluble organic compounds in biomass burning aerosols over Amazonial. Characterization by NMR and GCMS. J. Geophys. Res. 2002, 107 (D20), 8047.

(20) Lienhard, D. M.; Bones, D. L.; Zuend, A.; Krieger, U. K.; Reid, J. P.; Peter, T. Measurements of Thermodynamic and Optical Properties of Selected Aqueous Organic and Organic-Inorganic Mixtures of Atmospheric Relevance. J. Phys. Chem. A 2012, 116 (40), 9954-9968.

(21) Zardini, A. A.; Sjogren, S.; Marcolli, C.; Krieger, U. K.; Gysel, M.; Weingartner, E.; Baltensperger, U.; Peter, T. A combined particle trap/HTDMA hygroscopicity study of mixed inorganic/organic aerosol particles. Atmos. Chem. Phys. 2008, 8 (18), 5589-5601.

(22) Medeiros, P. M.; Simoneit, B. R. T. Source Profiles of Organic Compounds Emitted upon Combustion of Green Vegetation from Temperate Climate Forests. Environ. Sci. Technol. 2008, 42 (22), $8310-8316$.

(23) Steimer, S. S.; Lampimäki, M.; Coz, E.; Grzinic, G.; Ammann, $M$. The influence of physical state on shikimic acid ozonolysis: a case for in situ microspectroscopy. Atmos. Chem. Phys. 2014, 14 (19), 10761-10772.

(24) Steimer, S. S.; Berkemeier, T.; Gilgen, A.; Krieger, U. K.; Peter, T.; Shiraiwa, M.; Ammann, M. Shikimic acid ozonolysis kinetics of the transition from liquid aqueous solution to highly viscous glass. Phys. Chem. Chem. Phys. 2015, 17 (46), 31101-9.

(25) Berkemeier, T.; Steimer, S. S.; Krieger, U. K.; Peter, T.; Pöschl, U.; Ammann, M.; Shiraiwa, M. Ozone uptake on glassy, semi-solid and liquid organic matter and the role of reactive oxygen intermediates in atmospheric aerosol chemistry. Phys. Chem. Chem. Phys. 2016, 18 (18), 12662-74.

(26) Schauer, J. J.; Kleeman, M. J.; Cass, G. R.; Simoneit, B. R. T. Measurement of Emissions from Air Pollution Sources. 3. C1-C29 Organic Compounds from Fireplace Combustion of Wood. Environ. Sci. Technol. 2001, 35 (9), 1716-1728.

(27) Nolte, C. G.; Schauer, J. J.; Cass, G. R.; Simoneit, B. R. T. Highly Polar Organic Compounds Present in Wood Smoke and in the Ambient Atmosphere. Environ. Sci. Technol. 2001, 35, 1912-1919.

(28) George, C.; Strekowski, R. S.; Kleffmann, J.; Stemmler, K.; Ammann, M. Photoenhanced uptake of gaseous $\mathrm{NO}_{2}$ on solid organic compounds: a photochemical source of HONO? Faraday Discuss. 2005, 130, 195 .

(29) Ammann, M.; Rössler, E.; Strekowski, R.; George, C. Nitrogen dioxide multiphase chemistry: Uptake kinetics on aqueous solutions containing phenolic compounds. Phys. Chem. Chem. Phys. 2005, 7 (12), 2513-2518.

(30) Atkinson, R.; Baulch, D. L.; Cox, R. A.; Crowley, J. N.; Hampson, R. F.; Hynes, R. G.; Jenkin, M. E.; Rossi, M. J.; Troe, J. Evaluated kinetic and photochemical data for atmospheric chemistry: Volume I - gas phase reactions of $\mathrm{O}_{x}, \mathrm{HO}_{x}, \mathrm{NO}_{\mathrm{x}}$ and $\mathrm{SO}_{\mathrm{x}}$ species. Atmos. Chem. Phys. 2004, 4, 1461-1738.

(31) Kurylo, M. J.; Ouellette, P. A.; Laufer, A. H. Measurements of the preassure-dependence of the $\mathrm{HO}_{2}$ radical self-disproportionation reaction at 298K. J. Phys. Chem. 1986, 90 (3), 437-440.

(32) Lienhard, D. M.; Huisman, A. J.; Bones, D. L.; Te, Y. F.; Luo, B. P.; Krieger, U. K.; Reid, J. P. Retrieving the translational diffusion coefficient of water from experiments on single levitated aerosol droplets. Phys. Chem. Chem. Phys. 2014, 16 (31), 16677-83.
(33) Lamola, A. A.; Hammond, G. S. Mechanisms of Photochemical Reactions in Solution. XXXIII. Intersystem Crossing Efficiencies. J. Chem. Phys. 1965, 43 (6), 2129-2135.

(34) Song, Y. C.; Haddrell, A. E.; Bzdek, B. R.; Reid, J. P.; Bannan, T.; Topping, D. O.; Percival, C.; Cai, C. Measurements and Predictions of Binary Component Aerosol Particle Viscosity. J. Phys. Chem. A 2016, 120 (41), 8123-8137.

(35) Bertram, A. K.; Martin, S. T.; Hanna, S. J.; Smith, M. L.; Bodsworth, A.; Chen, Q.; Kuwata, M.; Liu, A.; You, Y.; Zorn, S. R. Predicting the relative humidities of liquid-liquid phase separation, efflorescence, and deliquescence of mixed particles of ammonium sulfate, organic material, and water using the organic-to-sulfate mass ratio of the particle and the oxygen-to-carbon elemental ratio of the organic component. Atmos. Chem. Phys. 2011, 11 (21), 1099511006.

(36) Renbaum-Wolff, L.; Song, M.; Marcolli, C.; Zhang, Y.; Liu, P. F.; Grayson, J. W.; Geiger, F. M.; Martin, S. T.; Bertram, A. K. Observations and implications of liquid-liquid phase separation at high relative humidities in secondary organic material produced by alfa-pinene ozonolysis without inorganic salts. Atmos. Chem. Phys. 2016, 16 (12), 7969-7979.

(37) Renbaum-Wolff, L.; Song, M. J.; Marcolli, C.; Zhang, Y.; Liu, P. F. F.; Grayson, J. W.; Geiger, F. M.; Martin, S. T.; Bertram, A. K. Observations and implications of liquid-liquid phase separation at high relative humidities in secondary organic material produced by alpha-pinene ozonolysis without inorganic salts. Atmos. Chem. Phys. 2016, 16 (12), 7969-7979.

(38) Lakey, P. S. J.; Berkemeier, T.; Krapf, M.; Dommen, J.; Steimer, S. S.; Whalley, L. K.; Ingham, T.; Baeza-Romero, M. T.; Pöschl, U.; Shiraiwa, M.; Ammann, M.; Heard, D. E. The effect of viscosity and diffusion on the $\mathrm{HO}_{2}$ uptake by sucrose and secondary organic aerosol particles. Atmos. Chem. Phys. 2016, 16 (20), 13035-13047.

(39) Jacques, P.; Allonas, X.; Von Raumer, M.; Suppan, P.; Haselbach, E. Quenching of triplet benzophenone by methyl and methoxy benzenes: are triplet exciplexes involved? J. Photochem. Photobiol., A 1997, 111 (1-3), 41-45.

(40) Battino, R; Rettich, T. R.; Tominaga, T. The Solubility of Oxygen and Ozone in Liquids. J. Phys. Chem. Ref. Data 1983, 12 (2), $163-178$

(41) Kanno, N.; Tonokura, K.; Tezaki, A.; Koshi, M. Water dependence of the $\mathrm{HO}_{2}$ self reaction: Kinetics of the $\mathrm{HO}_{2}-\mathrm{H}_{2} \mathrm{O}$ complex. J. Phys. Chem. A 2005, 109 (14), 3153-3158.

(42) Gržinić, G.; Bartels-Rausch, T.; Berkemeier, T.; Türler, A.; Ammann, M. Viscosity controls humidity dependence of $\mathrm{N}_{2} \mathrm{O}_{5}$ uptake to citric acid aerosol. Atmos. Chem. Phys. 2015, 15 (23), 1361513625 .

(43) Nagarajan, K.; Mallia, A. R.; Muraleedharan, K.; Hariharan, M. Enhanced intersystem crossing in core-twisted aromatics. Chem. Sci. 2017, 8 (3), 1776-1782.

(44) Ivković-Jensen, M. M.; Kostić, N. M. Effects of viscosity and temperature on the kinetics of the electron-transfer reaction between the triplet state of zinc cytochrome $c$ and cupriplastocyanin. Biochemistry 1997, 36 (26), 8135-8144.

(45) Mitroka, S.; Zimmeck, S.; Troya, D.; Tanko, J. M. How Solvent Modulates Hydroxyl Radical Reactivity in Hydrogen Atom Abstractions. J. Am. Chem. Soc. 2010, 132 (9), 2907-2913.

(46) Tatikolov, A. S.; Sklyarenko, V. I.; Kuzmin, V. A.; Alperovich, M. A. Effect of the solvent on reduction of azomethine dyes with ketyl radicals and recombination of ketyl radicals. Bull. Acad. Sci. USSR, Div. Chem. Sci. 1989, 38 (8), 1597-1601.

(47) Kunze, A.; Muller, U.; Tittes, K.; Fouassier, J. P.; Morlet-Savary, F. Triplet quenching by onium salts in polar and nonpolar solvents. J. Photochem. Photobiol., A 1997, 110 (2), 115-122.

(48) Dave, M. D.; Pande, U. C. Photoinduced electron transfer reaction of 2-mercaptothiazoline and methylene blue: Mechanism and kinetics. J. Chem. Pharm. Res. 2012, 4 (11), 4721-4730.

(49) Rossignol, S.; Aregahegn, K. Z.; Tinel, L.; Fine, L.; Noziere, B.; George, C. Glyoxal Induced Atmospheric Photosensitized Chemistry 
Leading to Organic Aerosol Growth. Environ. Sci. Technol. 2014, 48 (6), 3218-3227.

(50) Zhong, M.; Jang, M. Dynamic light absorption of biomassburning organic carbon photochemically aged under natural sunlight. Atmos. Chem. Phys. 2014, 14 (3), 1517-1525.

(51) Dusanter, S.; Vimal, D.; Stevens, P. S.; Volkamer, R.; Molina, L. T.; Baker, A.; Meinardi, S.; Blake, D.; Sheehy, P.; Merten, A.; Zhang, R.; Zheng, J.; Fortner, E. C.; Junkermann, W.; Dubey, M.; Rahn, T.; Eichinger, B.; Lewandowski, P.; Prueger, J.; Holder, H. Measurements of $\mathrm{OH}$ and $\mathrm{HO}_{2}$ concentrations during the MCMA-2006 field campaign - Part 2: Model comparison and radical budget. Atmos. Chem. Phys. 2009, 9 (18), 6655-6675.

(52) Tilgner, A.; Bräuer, P.; Wolke, R.; Herrmann, H. Modelling multiphase chemistry in deliquescent aerosols and clouds using CAPRAM3.0i. J. Atmos. Chem. 2013, 70 (3), 221-256.

(53) Kaur, R.; Anastasio, C. First Measurements of Organic Triplet Excited States in Atmospheric Waters. Environ. Sci. Technol. 2018, 52 (9), 5218-5226. 